\title{
HBV Genotype B/C and Response to Lamivudine Therapy: A Systematic Review
}

\author{
Xiu-Li Chen, ${ }^{1}$ Man $\mathrm{Li}^{2}{ }^{2}$ and Xiao-Lan Zhang ${ }^{1}$ \\ ${ }^{1}$ Department of Gastroenterology, The Second Hospital of Hebei Medical University, Hebei Key Laboratory of Gastroenterology, \\ Hebei Institute of Gastroenterology, No. 215 Heping West Road, Shijiazhuang 050000, China \\ ${ }^{2}$ Department of Epidemiology, School of Public Health, Hebei Medical University, Shijiazhuang, Hebei 050017, China
}

Correspondence should be addressed to Xiao-Lan Zhang; xiaolanzh@126.com

Received 23 July 2013; Revised 11 October 2013; Accepted 22 October 2013

Academic Editor: Xin Yao

Copyright (C) 2013 Xiu-Li Chen et al. This is an open access article distributed under the Creative Commons Attribution License, which permits unrestricted use, distribution, and reproduction in any medium, provided the original work is properly cited.

\begin{abstract}
A number of nucleoside analogues such as lamivudine (LAM), actually used for the treatment of chronic hepatitis B, can suppress HBV DNA replication, improve transaminase level and liver histology, and enhance the rate of hepatitis B e antigen (HBeAg) clearance. The responses to LAM therapy involve HBeAg clearance and HBV DNA conversion of negative. However, the associations between $\mathrm{HBV}$ genotype $\mathrm{B} / \mathrm{C}$ and response to LAM therapy remain ambiguous. The aim of this meta-analysis is to determine more precise estimations of the relationship. All the publications on the associations between HBV genotype B/C and response to LAM (HBeAg clearance and HBV DNA conversion of negative) through June 2013 were collected. Relative risk (RR) with $95 \%$ confidence intervals ( $95 \%$ CI) was calculated in fixed or random model, $I^{2}$ was calculated to examine heterogeneity, and funnel plots were plotted to examine small study effects with Stata 11 software. Overall, for $\mathrm{HBeAg}$ clearance and genotype B/C, the RR (95\% CI) was 1.27 (0.94-1.71), while for HBV DNA conversion of negative and genotype B/C, the RR (95\% CI) was 1.07 (0.98-1.17). HBV genotype B/C shows no significance associations with response to lamivudine therapy (HBeAg clearance and HBV DNA conversion of negative).
\end{abstract}

\section{Introduction}

Hepatitis B virus (HBV) infection is one of the major causes of hepatic cirrhosis and hepatocellular carcinoma in endemic areas [1]; the current study has determined that the different HBV genotypes have very important impacts on response to antiviral therapy $[2,3]$, in particular interferon treatment. LAM as a potent inhibitor of HBV reverse transcriptase activity is able to decrease serum HBV-DNA levels and improve the rate of $\mathrm{HBeAg} / \mathrm{anti}-\mathrm{HBe}$ seroconversion in patients with chronic hepatitis $\mathrm{B}(\mathrm{CHB})$. In regard to genotypes $\mathrm{B}$ and $\mathrm{C}$, the Asian literature shows no difference in the antiviral (biochemical and virologic) response after 1 year of treatment with LAM $100 \mathrm{mg} /$ daily orally in patients affected by HBeAg positive hepatitis [4-7]. These studies did not come into the conclusion and did not include some studies published recently. Data concerning the relevance of HBV genotypes in relation to response to LAM therapy are less clear. A metaanalysis is needed to combine all studies. Then in the present study, we will pool the data available and investigate the associations between genotypes $\mathrm{B} / \mathrm{C}$ and response to LAM therapy susceptibility.

\section{Methods}

2.1. Testing Method. HBeAg and anti-HBe were tested by chemiluminescence enzyme immunoassay (CLEIA). The serum HBV DNA level in all the samples was quantified by the real-time PCR method. The detection limit of this assay was 100 copies $/ \mathrm{mL}$. The HBV genotype was determined by restriction fragment length polymorphism.

2.2. Study Selection. Several databases (PubMed, Web of Science, Science Direct, and CNKI Database) were searched through June 2012 for all publications on the association between genotype $\mathrm{B} / \mathrm{C}$ and response to LAM therapy. The search terms were as follows: "genotype B" or "genotype 


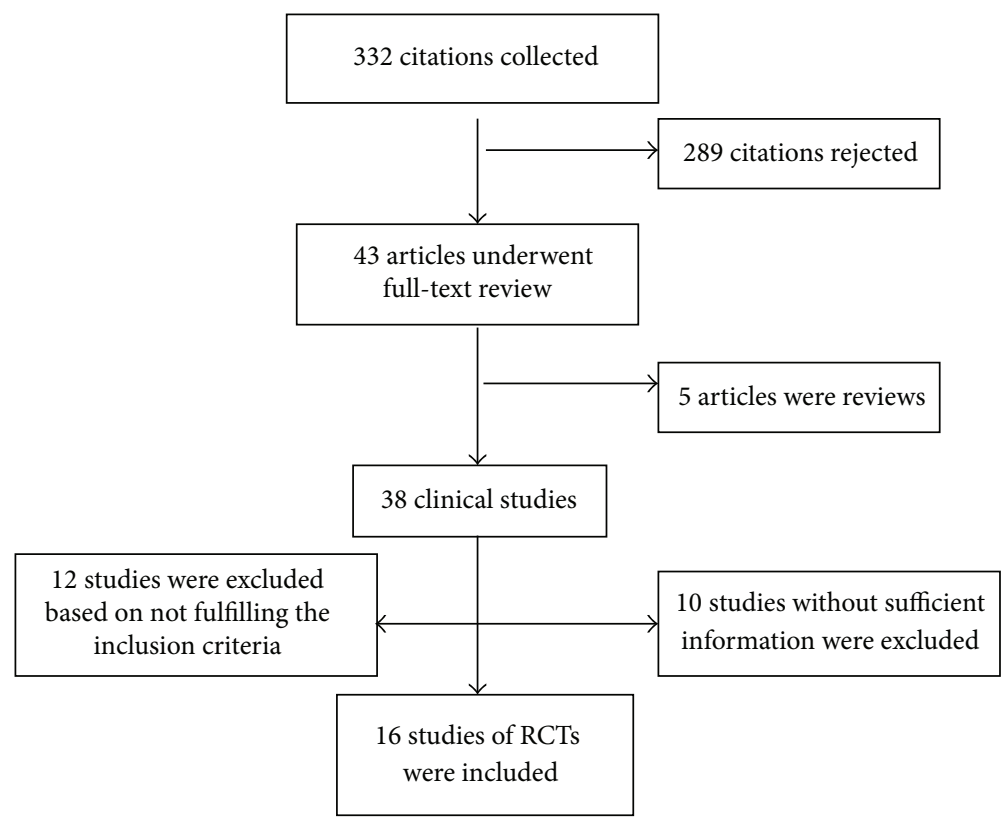

FIgURE 1: Flow diagram of the systematic literature research.

C," "LAM," "HBeAg clearance," and "DNA conversion of negative." In addition, we also searched references of retrieved articles.

2.3. Inclusion and Exclusion Criteria. The following inclusion criteria were used. Useful data were extracted with standardized data-extraction forms. Studies published in English and Chinese were eligible if they fulfilled the following criteria: (1) studies in the mentioned four databases with full text; (2) study data from published randomized controlled trials (RCTs); (3) the objects being $\mathrm{CHB}$ patients under lamivudine treatment with $100 \mathrm{mg}$ daily, for 48 weeks, without other treatment measures taken at the same time; and (4) sufficient published data for estimating RR with $95 \%$ confidence inter$\operatorname{val}(\mathrm{CI})$.

Studies were excluded if (1) study objects were patients with acute hepatitis B; (2) they were subset of a published article by the same authors; (3) studies present unclear data or obviously paradoxical data; (4) patients had received lamivudine therapy less than 12 months. Finally, we found 19 studies (16 articles), in which 9 studies were on the associations between genotype $\mathrm{B} / \mathrm{C}$ and $\mathrm{HBeAg}$ clearance [816 ] and 10 studies between genotype $B / C$ and $H B V$ DNA conversion of negative $[11,12,15,17-23]$.

2.4. Evaluation Criteria. Primary end point of effectiveness of response was assessed after 24 weeks of treatment-free followup: HBeAg seroconversion (defined by the loss of $\mathrm{HBeAg}$ and the presence of anti-HBe antibody) and suppression of HBV DNA to levels below 100,000 copies per milliliter. Secondary end point of effectiveness of response assessed after 24 weeks included the combined response (HBeAg seroconversion, the normalization of alanine aminotransferase levels, and the suppression of HBV DNA levels to below 100,000 copies per milliliter), HBsAg seroconversion (defined by the loss of HBsAg and the presence of anti-HBs antibody), and the histologic response. A histologic response was defined as a reduction of at least two points in the modified Histologic Activity Index score as compared with the pretreatment score.

2.5. Data Extraction. The following items were extracted from the literature: first author's last name, publication date, journal title, sample size, the status of HBeAg (positive or negative), the amount of serum HBV DNA (copies/mL), and $\mathrm{HBV}$ genotype. All the numerical values of HBV DNA copies were converted to logarithm.

2.6. Statistical Analysis. Statistical analysis Review Manager 5.1 and Stata 11 software were used to perform meta-analysis. RR with 95\% CIs were calculated in a fixed- or randomeffect model to assess the strength of the association between genotype $\mathrm{B} / \mathrm{C}$ and response to LAM therapy. Heterogeneity among studies was examined with $I$ square $\left(I^{2}\right)$ statistic [24] interpreted as the proportion of total variation contributed by between-study variation. If there was a statistical difference in terms of heterogeneity $(P<0.05)$, a random-effect model was selected to pool the data. A fixed-effect model, otherwise, was employed. Begg's funnel plot was used to examine small study effects. The method of Begg and Mazumdar [25] was used to calculate $P$ for rank correlation and Egger's weighted regression method [26] to calculate $P$ for bias. Throughout the paper, for HBeAg clearance $(t=0.18, P=0.861)$ and for DNA conversion of negative $(t=2.28, P=0.052)$, two-sided $P$ values $<0.05$ were considered as statistically significant.

\section{Results}

3.1. Search Results and Characteristics. We identified 332 relevant literatures via electronic searches, the overlap studies 


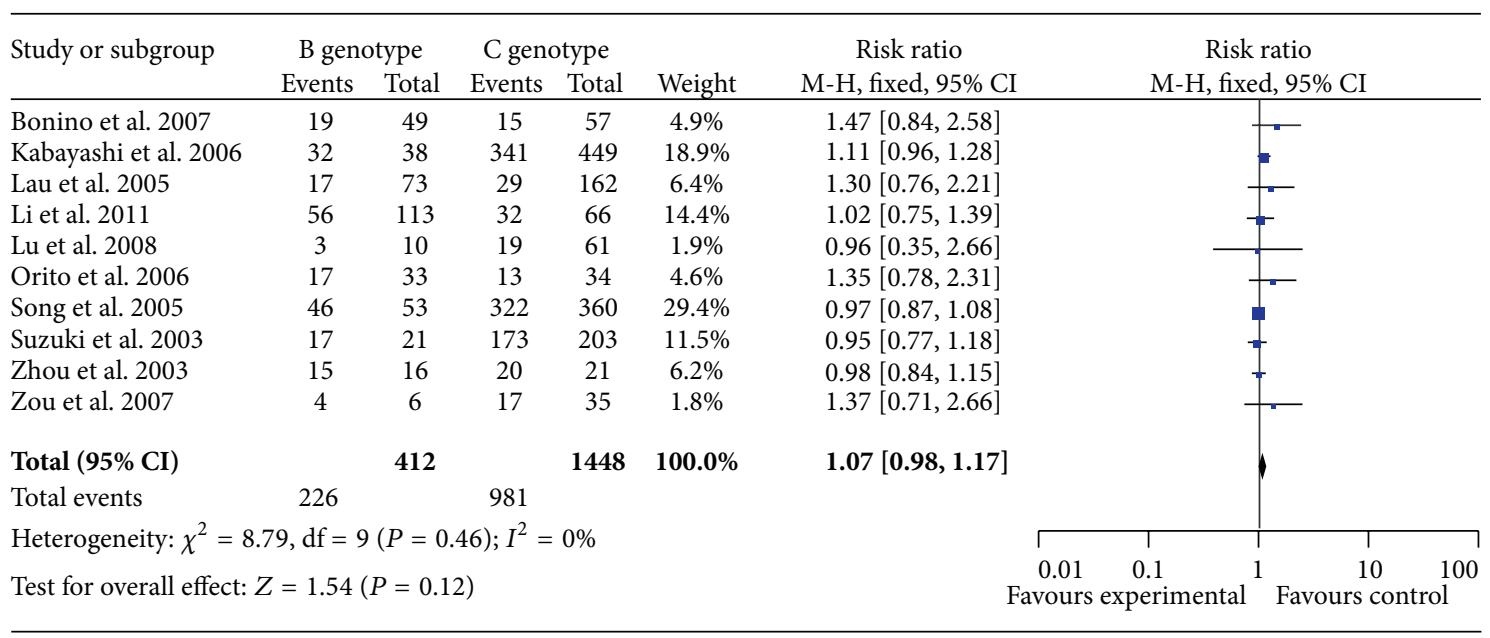

(a)

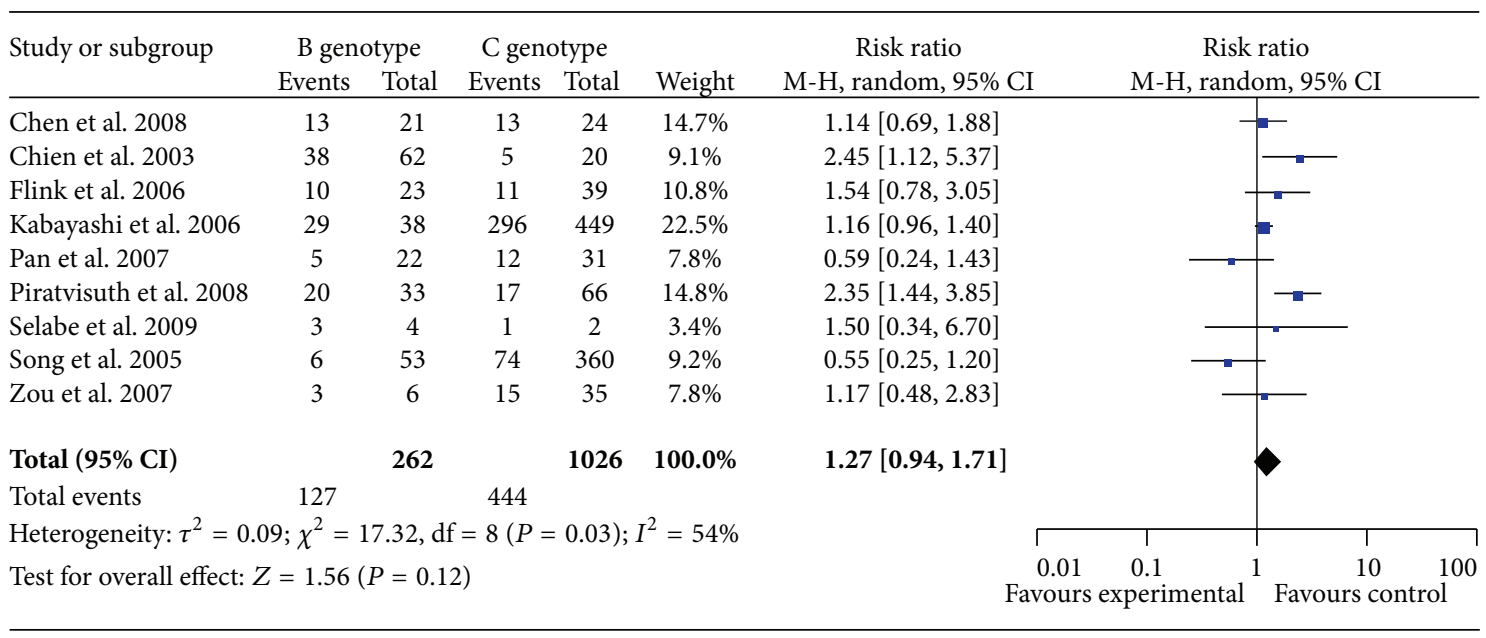

(b)

FIGURE 2: Forest plot for the associations of genotype B/C and HBV DNA conversion of negative (a) or HBeAg clearance (b) to lamivudine therapy.

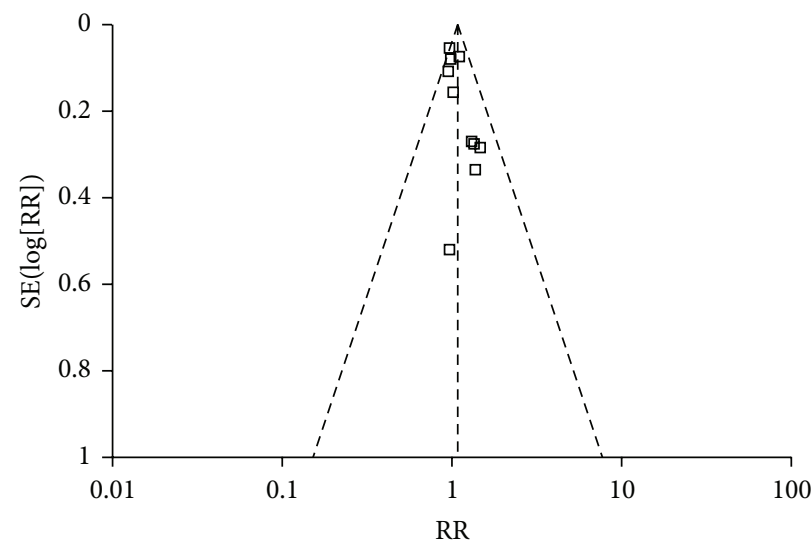

(a)

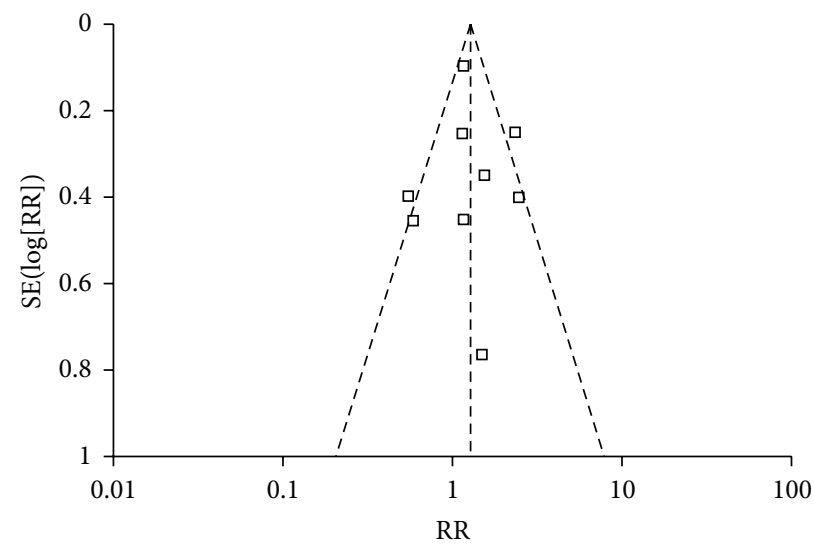

(b)

Figure 3: Begg's funnel plots for the associations of genotype B/C and HBV DNA conversion of negative (a) or HBeAg clearance (b) to lamivudine therapy. 
TABLE 1: Characteristics of HBV DNA studies included in the meta-analysis.

\begin{tabular}{lccccccc}
\hline Author & Year & $N$ & Age (years) & Gender (M\%) & Genotype (B/C) & Severity of liver disease & HBVDNA (log copies/mL) \\
\hline Lu et al. [17] & 2008 & 71 & $32 \pm 9.0$ & 83 & $10 / 61$ & CHB & $7.7 \pm 0.8$ \\
Li et al. [18] & 2011 & 179 & $35.4 \pm 10.3$ & 80 & $113 / 66$ & CHB & $9.4 \pm 1.3$ \\
Orito et al. [19] & 2006 & 67 & $41.5 \pm 12.2$ & 67 & $33 / 34$ & CHB & $10.7 \pm 1.1$ \\
Zou et al. [11] & 2007 & 41 & $32.1 \pm 9.6$ & 85 & $6 / 35$ & CHB & $5.8 \pm 1.2$ \\
Song et al. [12] & 2005 & 413 & - & - & $53 / 360$ & CHB & - \\
Bonino et al. [20] & 2007 & 106 & $37.9 \pm 10.6$ & 82 & $49 / 57$ & CHB & $8.9 \pm 1.1$ \\
Lau et al. [21] & 2005 & 235 & $31.6 \pm 9.7$ & 91 & $73 / 162$ & CHB & $10.1 \pm 2.0$ \\
Kobayashi et al. [15] & 2006 & 487 & $45.1 \pm 13.1$ & 86 & $38 / 449$ & CHB & $7.2 \pm 0.0$ \\
Suzuki et al. [22] & 2003 & 224 & $46 \pm 12.1$ & - & $21 / 203$ & CHB & $9.1 \pm 1.6$ \\
Zhou et al. [23] & 2003 & 37 & - & - & $16 / 21$ & CHB & $8.3 \pm 1.2$ \\
\hline
\end{tabular}

$N$ : numbers of patients; CHB: chronic hepatitis B.

TABLE 2: Characteristics of HBeAg studies included in the meta-analysis.

\begin{tabular}{|c|c|c|c|c|c|c|c|}
\hline Author & Year & $N$ & Age & Sex & Genotype B/C & Severity of liver disease & $\mathrm{HBeAg}$ \\
\hline Zou et al. [11] & 2007 & 41 & $32.1 \pm 9.6$ & 85 & $6 / 35$ & $\mathrm{CHB}$ & $\overline{\text { Positive }}$ \\
\hline Song et al. [12] & 2005 & 413 & - & - & $53 / 360$ & $\mathrm{CHB}$ & Positive \\
\hline Kobayashi et al. [15] & 2006 & 487 & $45.1 \pm 13.1$ & 81 & $38 / 449$ & $\mathrm{CHB}$ & Positive \\
\hline Flink et al. [8] & 2006 & 62 & $34 \pm 9.0$ & 69 & $23 / 39$ & $\mathrm{CHB}$ & Positive \\
\hline Pan et al. [9] & 2007 & 53 & $53 \pm 12$ & 57 & $22 / 31$ & $\mathrm{CHB}$ & Positive \\
\hline Piratvisuth et al. [10] & 2008 & 99 & - & - & $33 / 66$ & $\mathrm{CHB}$ & Positive \\
\hline Chen et al. [13] & 2008 & 45 & $30 \pm 10.7$ & 76 & $21 / 24$ & $\mathrm{CHB}$ & Positive \\
\hline Selabe et al. [14] & 2009 & 6 & $45 \pm 12.6$ & 83 & $4 / 2$ & $\mathrm{CHB}$ & Positive \\
\hline Chien et al. [16] & 2003 & 82 & $33.8 \pm 11.1$ & 77 & $62 / 20$ & $\mathrm{CHB}$ & Positive \\
\hline
\end{tabular}

$N$ : numbers of patients; CHB: chronic hepatitis B.

were excluded, and finally 19 studies on randomized controlled trials (RCTs) were left for analysis which involved 3148 patients in total (who were included in LAM therapy groups) (Figure 1). All included trials had clearly stated inclusion and exclusion criteria. Of the 19 studies, 4 were published in Chinese $[11-13,17]$ and the others were published in English [8-10, 14-16, 18-23]. This meta-analysis identified 10 studies with a total number of 1860 cases for HBV DNA conversion of negative (and 9 studies with 1288 cases for $\mathrm{HBeAg}$ clearance), and the detailed information of included RCTs was summarized in Tables 1 and 2.

3.2. HBV DNA Conversion of Negative. According to chisquared statistic and $I^{2}$, heterogeneity was assessed and was not found to be a concern. For HBV DNA conversion of negative, the overall RR (95\% CI) associated with genotype B/C was 1.07 (0.98-1.17) (Figure 2(a)). Begg's funnel plot for the association between HBV DNA conversion of negative and genotype $\mathrm{B} / \mathrm{C}$ was shown in Figure 3(a), in which $x$-axis is RR and $y$-axis is standard error (SE). No bias was observed for $\mathrm{HBV}$ DNA conversion of negative versus genotype $\mathrm{B} / \mathrm{C}$ in Egger's test $(P=0.052)$. There was no heterogeneity in overall analysis $\left(I^{2}=0, P=0.46\right)$.

3.3. Hepatitis $B$ e Antigen Clearance. According to chisquared statistic and $I^{2}$, heterogeneity was assessed and $I^{2}$ showed moderate degree heterogeneity among studies
$\left(I^{2}=54 \%, P=0.03\right)$. Of the nine analyzed trials, HBeAg clearance was observed in genotype $\mathrm{B}$ group as compared with that genotype C group, the overall RR (95\% CIs) was 1.27 (0.94-1.71) (Figure 2(b)), and Begg's funnel plot for the association between $\mathrm{HBeAg}$ clearance and genotype $\mathrm{B} / \mathrm{C}$ was shown in Figure 3(b), in which $x$-axis is RR and $y$-axis is standard error (SE). Smaller studies which lie in the righthand side of the graph often have larger SEs. There was no evidence for bias using Egger's weighted regression method $(P=0.861)$.

\section{Discussion}

Chronic HBV infection is a dynamic state of interactions between the virus, hepatocytes and the host immune response [27-29]. HBV genotypes (A to H) can be classified based on comparison of complete HBV genomes and in accordance with the criterion of $8 \%$ or more differences in the complete nucleotide sequence of the viral genome $[2,3]$. Genotypes B and C are common in the majority of Asian countries. In fact, with regard to HBV genotypes $\mathrm{B}$ and $\mathrm{C}$, which are prevalent in Asia, genotype $\mathrm{C}$ has been shown to be more frequently found in severe liver disease and in hepatocellular carcinoma, whereas genotype $\mathrm{B}$ is associated with faster $\mathrm{HBeAg} / \mathrm{anti}-\mathrm{HBe}$ seroconversion during acute hepatitis [30-32]. At present, it is not clear whether viral genotype is a predictor of treatment response in 
chronic hepatitis B, as it is in chronic hepatitis C. Responses to all genotypes, nucleoside or nucleotide analogues are generally consistent among all genotypes. To our knowledge, no systematic review has been previously published on the association between genotype $\mathrm{B} / \mathrm{C}$ and response to LAM therapy.

In this meta-analysis, all informed consent of patients were obtained. $\mathrm{CHB}$ patients received lamivudine, $100 \mathrm{mg}$ daily, for 48 weeks, without other treatment measures taken at the same time. The patients with normal ALT levels (40 IU/L or less) before commencement of the treatment were excluded. All patients were positive for HBsAg for more than 6 months and negative for both HCV and antiHIV. All patients were tested by ultrasonography or CT scan to rule out decompensated cirrhosis or hepatocellular carcinoma.

Response rates were calculated for all patients according to the intention-to-treat principle. For the patients, who received at least one dose of study drug, including both HBeAg and HBV DNA groups, the response rate of $\mathrm{HBV}$ DNA to lamivudine therapy about HBV genotype B/C was defined as the ratio of the HBV DNA conversion of negative, and the response rate of $\mathrm{HBeAg}$ to lamivudine therapy about $\mathrm{HBV}$ genotype $\mathrm{B} / \mathrm{C}$ was defined as the ratio of the $\mathrm{HBeAg}$ clearance. HBeAg clearance was evaluated in 1288 patients with $\mathrm{CHB}$ who received LAM therapy between patients with genotype $\mathrm{B}$ and genotype C. Results from currently available studies suggest that HBeAg clearance was observed in genotype $\mathrm{B}$ group as compared with genotype $\mathrm{C}$; the overall RR (95\% CI) was 1.27 (0.94-1.71). The present study showed that genotype $\mathrm{B} / \mathrm{C}$ was negatively associated with HBeAg clearance to LAM therapy. While a retrospectiveprospective study suggested that genotype $B$, age less than 36 years, and additional LAM treatment over 8 months after HBeAg seroconversion showed a sustained $\mathrm{HBeAg}$ response up to $80 \%(P<0.005)[16]$, this study indicates that age and additional treatment may be the major determinants [33-35].

A total of 10 studies were included in following analysis. The results showed no differences in terms of HBV DNA conversion of negative at week 52, between patients with genotype $\mathrm{B}$ and genotype $\mathrm{C}$, which agree with the outcomes of previous studies [19-23, 36-38]; the overall RR (95\% CIs) was 1.07 (0.98-1.17). No association was found between genotype $\mathrm{B} / \mathrm{C}$ and HBV DNA conversion of negative to LAM therapy. Funnel plots and two formal statistical methods were used to detect bias.

It should be noted that some limitations existed in this meta-analysis. It is well known to us that many factors influence the outcomes to LAM therapy, including country of origin, ethnicity, age, gender, severity of liver disease, baseline of HBV DNA, numbers of cases and controls, and genotyping method, which may introduce errors in analysis.

In conclusion, this meta-analysis indicated that genotype $\mathrm{B} / \mathrm{C}$ was not associated with response to LAM therapy (HBeAg seroclearance and HBV DNA conversion of negative). Further mechanism researches are required to clarify. Large-scale population studies in multicountries are also necessary to evaluate the influence of HBV genotypes in hepatitis B progression and antiviral treatment.

\section{Conflict of Interests}

The authors declare that there is no conflict of interests.

\section{Authors' Contribution}

Xiu-Li Chen conceived and designed the research; Man Li and Xiu-Li Chen analyzed the data; Xiu-Li Chen and XiaoLan Zhang wrote the paper.

\section{References}

[1] J. L. Dienstag, "Drug therapy: hepatitis B virus infection," The New England Journal of Medicine, vol. 359, no. 14, pp. 1486-1500, 2008.

[2] S. Schaefer, "Hepatitis B virus taxonomy and hepatitis B virus genotypes," World Journal of Gastroenterology, vol. 13, no. 1, pp. $14-21,2007$.

[3] A. Bartholomeusz and S. Schaefer, "Hepatitis B virus genotypes: comparison of genotyping methods," Reviews in Medical Virology, vol. 14, no. 1, pp. 3-16, 2004.

[4] A. Zeng, H. Deng, C. Yang et al., "Hepatitis B virus genotypeassociated variability in antiviral response to adefovir dipivoxil therapy in Chinese han population," Tohoku Journal of Experimental Medicine, vol. 216, no. 3, pp. 205-211, 2008.

[5] G. Zeng, Z. Wang, S. Wen et al., "Geographic distribution, virologic and clinical characteristics of hepatitis B virus genotypes in China," Journal of Viral Hepatitis, vol. 12, no. 6, pp. 609-617, 2005.

[6] I. Carey and P. M. Harrison, "Monotherapy versus combination therapy for the treatment of chronic hepatitis B," Expert Opinion on Investigational Drugs, vol. 18, no. 11, pp. 1655-1666, 2009.

[7] E. Palumbo, "Hepatitis B genotypes and response to antiviral therapy: a review," American Journal of Therapeutics, vol. 14, no. 3, pp. 306-309, 2007.

[8] H. J. Flink, M. van Zonneveld, B. E. Hansen, R. A. de Man, S. W. Schalm, and H. L. A. Janssen, "Treatment with Peginterferon $\alpha$-2b for HBeAg-positive chronic hepatitis B: HBsAg loss is associated with HBV genotype," American Journal of Gastroenterology, vol. 101, no. 2, pp. 297-303, 2006.

[9] X. P. Pan, L. J. Li, W. B. Du, M. W. Li, H. C. Cao, and J. F. Sheng, "Differences of YMDD mutational patterns, precore/core promoter mutations, serum HBV DNA levels in lamivudine-resistant hepatitis B genotypes B and C,' Journal of Viral Hepatitis, vol. 14, no. 11, pp. 767-774, 2007.

[10] T. Piratvisuth, G. Lau, Y. Chao et al., "Sustained response to peginterferon alfa-2a $(40 \mathrm{kD})$ with or without lamivudine in Asian patients with $\mathrm{HBeAg}$-positive and HBeAg-negative chronic hepatitis B," Hepatology International, vol. 2, no. 1, pp. 102-110, 2008.

[11] H. Zou, L. Zhu, G. Zhao et al., "The relationship between HBV genotypes and the efficacy of antiviral therapies in hepatitis B e antigen-positive patients," Zhonghua Gan Zang Bing Za Zhi, vol. 15, no. 6, pp. 425-427, 2007.

[12] S. Song, H. Zhuang, J. Yan et al., "Relationship between B virus hepatitis genotypes and therapeutic efficacy in early treatment for chronic hepatitis B by using lamivudine," Zhonghua Yu Fang Yi Xue Za Zhi, vol. 39, no. 3, pp. 203-205, 2005.

[13] J. Chen, Z. Wang, S. Ma et al., "Changes of serum HBsAg in $\mathrm{HBeAg}$ positive chronic hepatitis patients with sustained viral 
response to long-term lamivudine treatment," Zhonghua Gan Zang Bing Za Zhi, vol. 16, no. 6, pp. 416-420, 2008.

[14] S. G. Selabe, E. Song, R. J. Burnett, and M. J. Mphahlele, "Frequent detection of hepatitis B virus variants associated with lamivudine resistance in treated South African patients infected chronically with different HBV genotypes," Journal of Medical Virology, vol. 81, no. 6, pp. 996-1001, 2009.

[15] M. Kobayashi, F. Suzuki, N. Akuta et al., "Response to long-term lamivudine treatment in patients infected with hepatitis B virus genotypes A, B, and C," Journal of Medical Virology, vol. 78, no. 10, pp. 1276-1283, 2006.

[16] R. Chien, C. Yeh, S. Tsai, C. Chu, and Y. Liaw, "Determinants for sustained HBeAg response to lamivudine therapy," Hepatology, vol. 38, no. 5, pp. 1267-1273, 2003.

[17] H. Lu, L. Zhuang, Y. Yu, C. Si, and J. Li, "Effects of antiviral agents on intrahepatic ccc DNA in HBeAg-positive chronic hepatitis B patients," Zhonghua Gan Zang Bing Za Zhi, vol. 16, no. 3, pp. 198-202, 2008.

[18] S. Li, L. Qin, L. Zhang et al., "Molecular epidemical characteristics of Lamivudine resistance mutations of HBV in southern China," Medical Science Monitor, vol. 17, no. 10, pp. PH75-PH80, 2011.

[19] E. Orito, K. Fujiwara, Y. Tanaka et al., "A case-control study of response to lamivudine therapy for 2 years in Japanese and Chinese patients chronically infected with hepatitis B virus of genotypes Bj, Ba and C," Hepatology Research, vol. 35, no. 2, pp. 127-134, 2006.

[20] F. Bonino, P. Marcellin, G. K. K. Lau et al., "Predicting response to peginterferon $\alpha-2 \mathrm{a}$, lamivudine and the two combined for HBeAg-negative chronic hepatitis B," Gut, vol. 56, no. 5, pp. 699-705, 2007.

[21] G. K. K. Lau, T. Piratvisuth, X. L. Kang et al., "Peginterferon Alfa-2a, lamivudine, and the combination for HBeAg-positive chronic hepatitis B," The New England Journal of Medicine, vol. 352, no. 26, pp. 2682-2695, 2005.

[22] F. Suzuki, A. Tsubota, Y. Arase et al., "Efficacy of lamivudine therapy and factors associated with emergence of resistance in chronic hepatitis B virus infection in Japan," Intervirology, vol. 46, no. 3, pp. 182-189, 2003.

[23] D. Zhou, L. Lin, H. Wang, and J. Huang, "The relationship between HBV lamivudine resistance and HBV genotypes or basic core promoter mutations," Hepatobiliary and Pancreatic Diseases International, vol. 2, no. 1, pp. 85-89, 2003.

[24] J. P. T. Higgins, S. G. Thompson, J. J. Deeks, and D. G. Altman, "Measuring inconsistency in meta-analyses," British Medical Journal, vol. 327, no. 7414, pp. 557-560, 2003.

[25] C. B. Begg and M. Mazumdar, "Operating characteristics of a rank correlation test for publication bias," Biometrics, vol. 50, no. 4, pp. 1088-1101, 1994.

[26] M. Egger, G. D. Smith, M. Schneider, and C. Minder, "Bias in meta-analysis detected by a simple, graphical test," British Medical Journal, vol. 315, no. 7109, pp. 629-634, 1997.

[27] J. Pawlotsky, G. Dusheiko, A. Hatzakis et al., "Virologic monitoring of hepatitis B virus therapy in clinical trials and practice: recommendations for a standardized approach," Gastroenterology, vol. 134, no. 2, pp. 405-415, 2008.

[28] H. Sumi, O. Yokosuka, N. Seki et al., "Influence of hepatitis $\mathrm{B}$ virus genotypes on the progression of chronic type B liver disease," Hepatology, vol. 37, no. 1, pp. 19-26, 2003.

[29] C. Liu, W. Huang, P. Chen, M. Lai, J. Kao, and D. Chen, "Endof-treatment virologic response does not predict relapse after lamivudine treatment for chronic hepatitis B," World Journal of Gastroenterology, vol. 10, no. 24, pp. 3574-3578, 2004.

[30] I. Merican, R. Guan, D. Amarapuka et al., "Chronic hepatitis B virus infection in Asian countries," Journal of Gastroenterology and Hepatology, vol. 15, no. 12, pp. 1356-1361, 2000.

[31] M.-F. Yuen, H.-J. Yuan, D. K.-H. Wong et al., "Prognostic determinants for chronic hepatitis B in Asians: therapeutic implications," Gut, vol. 54, no. 11, pp. 1610-1614, 2005.

[32] N. Leung, "Treatment of chronic hepatitis B: case selection and duration of therapy," Journal of Gastroenterology and Hepatology, vol. 17, no. 4, pp. 409-414, 2002.

[33] S. Villet, C. Pichoud, G. Billioud et al., "Impact of hepatitis B virus rtA181V/T mutants on hepatitis B treatment failure," Journal of Hepatology, vol. 48, no. 5, pp. 747-755, 2008.

[34] J. J. Y. Sung, J. Lai, S. Zeuzem et al., "Lamivudine compared with lamivudine and adefovir dipivoxil for the treatment of $\mathrm{HBeAg}$ positive chronic hepatitis B," Journal of Hepatology, vol. 48, no. 5, pp. 728-735, 2008.

[35] H. L. Chan, M. Wong, A. Y. Hui et al., "Hepatitis B virus genotype has no impact on hepatitis $\mathrm{B}$ e antigen seroconversion after lamivudine treatment," World Journal of Gastroenterology, vol. 9, no. 12, pp. 2695-2697, 2003.

[36] M. Economou, S. Manolakopoulos, T. A. Trikalinos et al., "Interferon- $\alpha$ plus lamivudine vs lamivudine reduces breakthroughs, but does not affect sustained response in $\mathrm{HBeAg}$ negative chronic hepatitis B," World Journal of Gastroenterology, vol. 11, no. 37, pp. 5882-5887, 2005.

[37] M. Sheu, H. Kuo, C. Lin et al., "Lamivudine monotherapy for chronic hepatitis B infection with acute exacerbation revisited," European Journal of Gastroenterology and Hepatology, vol. 21, no. 4, pp. 447-451, 2009.

[38] M. Buti, I. Elefsiniotis, R. Jardi et al., "Viral genotype and baseline load predict the response to adefovir treatment in lamivudine-resistant chronic hepatitis B patients," Journal of Hepatology, vol. 47, no. 3, pp. 366-372, 2007. 


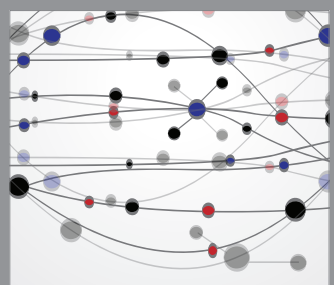

The Scientific World Journal
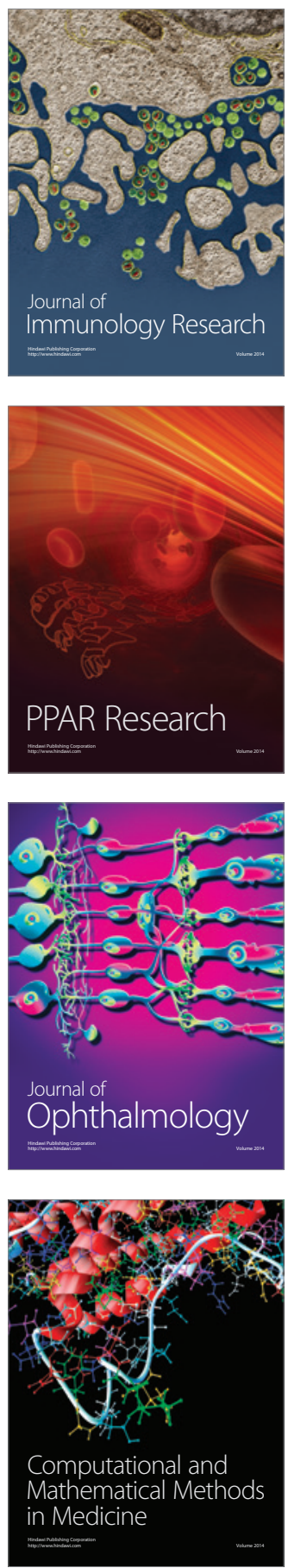

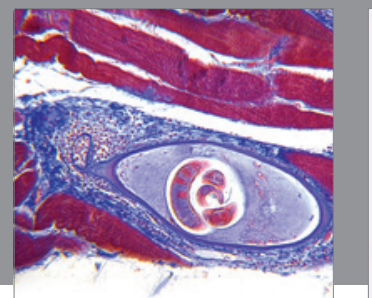

Gastroenterology

Research and Practice
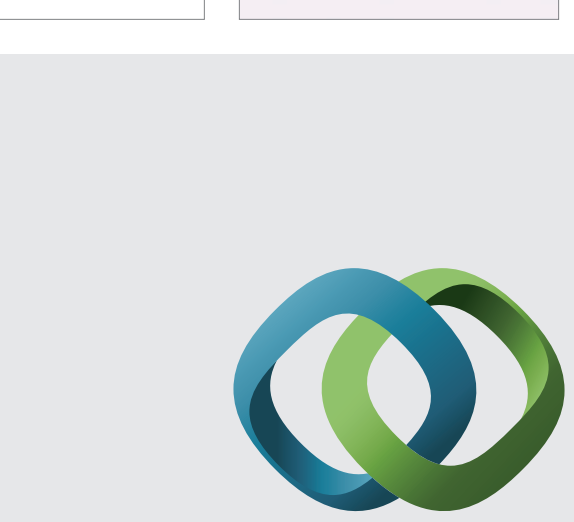

\section{Hindawi}

Submit your manuscripts at

http://www.hindawi.com
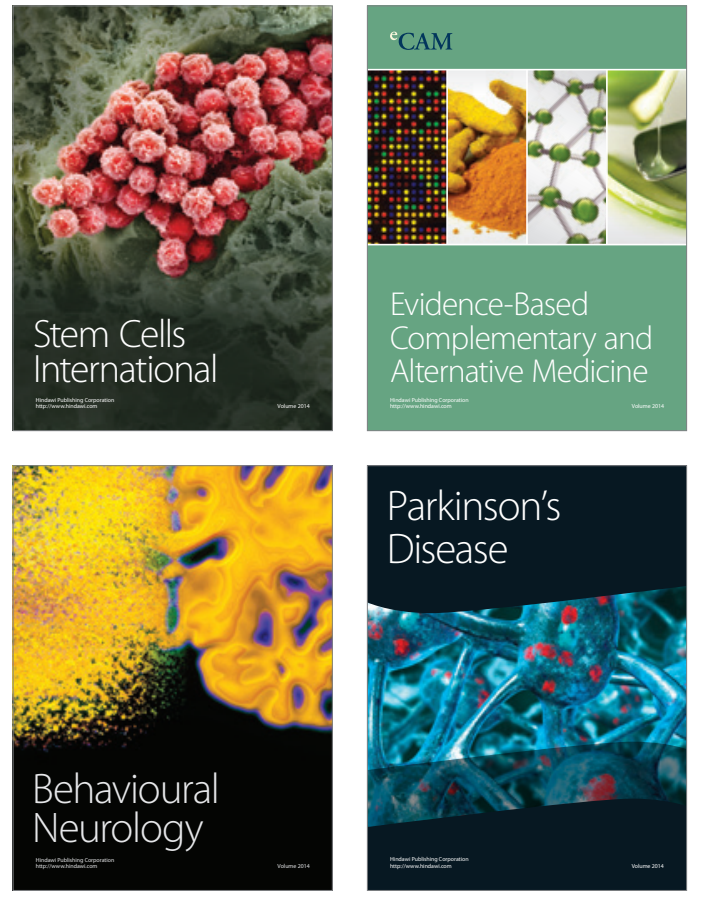
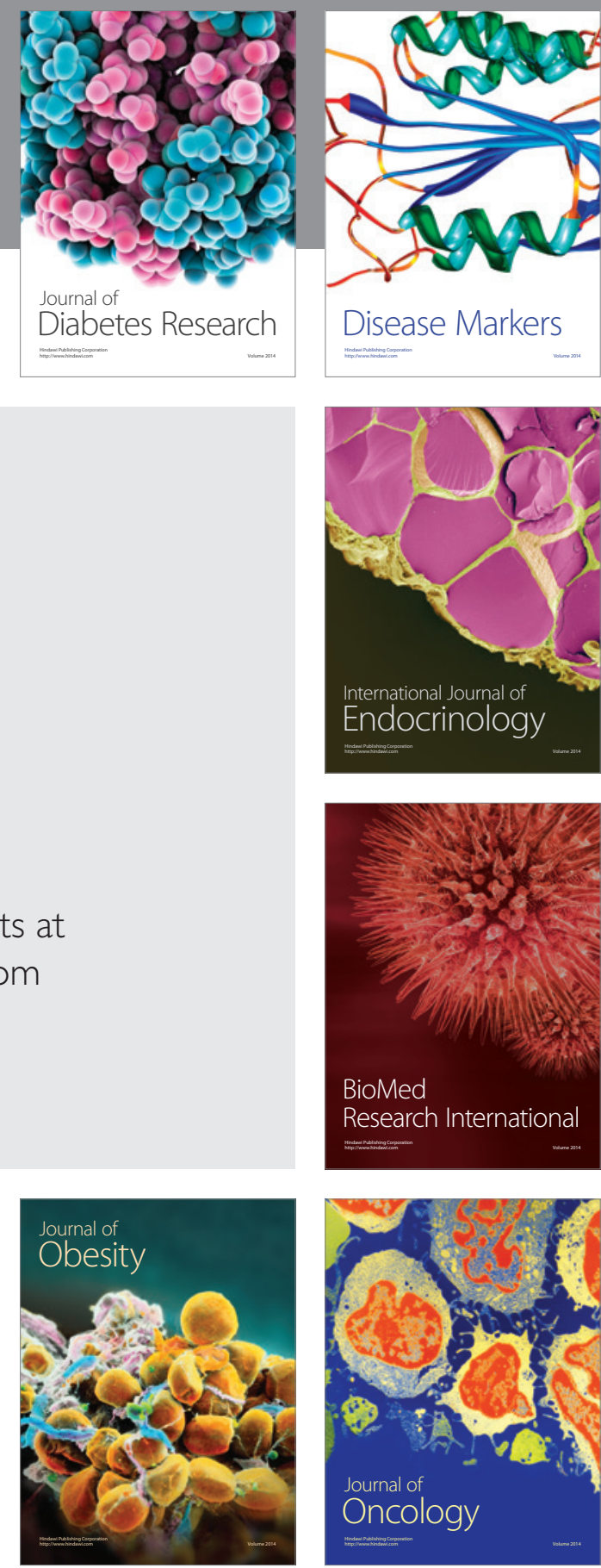

Disease Markers
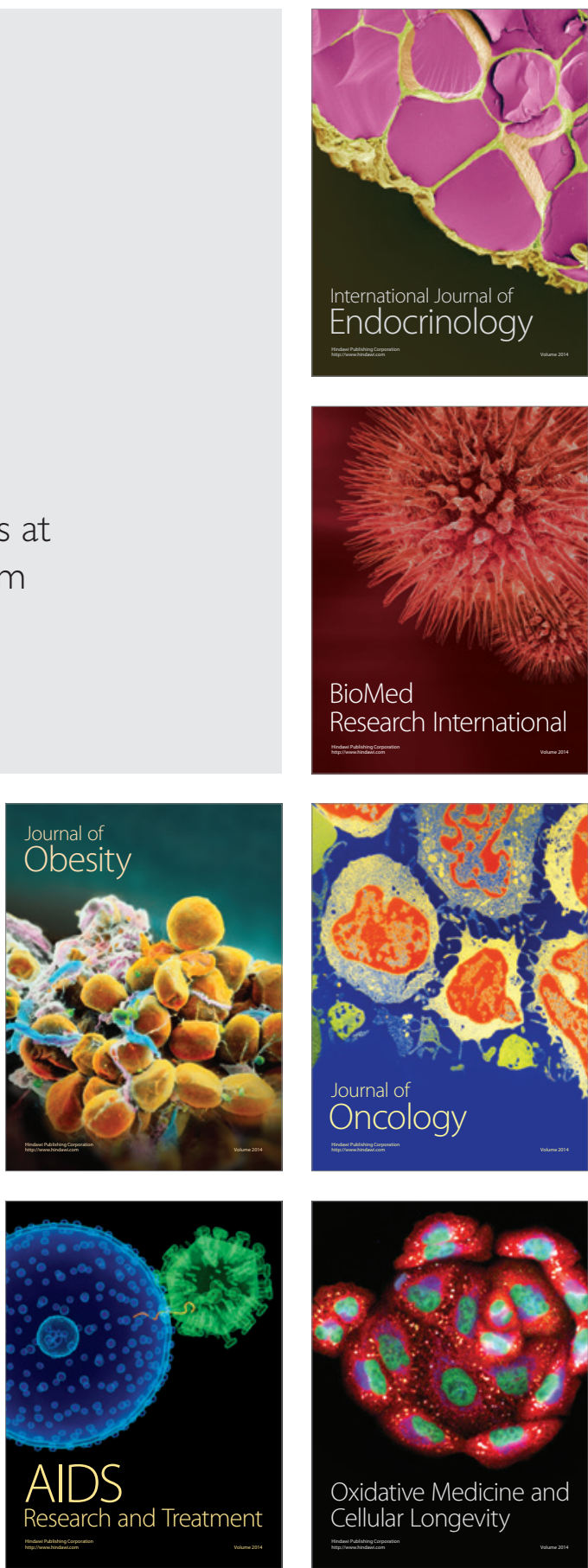